\title{
Cocaine abuse induced diffuse alveolar haemorrhage: a rare entity
}

\author{
Manas Mengar ${ }^{1}$, Nitesh Gupta ${ }^{1}$, Shibdas Chakrabarti ${ }^{1}$, Vipin Aggarwal ${ }^{1}$, Kalindi Shah ${ }^{2}$, Pranav Ish ${ }^{1}$ \\ ${ }^{1}$ Department of Pulmonary, Critical Care and Sleep Medicine, Vardhman Mahavir Medical College and Safdarjung \\ Hospital, New Delhi; ${ }^{2}$ Department of Anaesthesiology, Vardhman Mahavir Medical College and Safdarjung Hospital, \\ New Delhi, India
}

\begin{abstract}
Diffuse alveolar haemorrhage (DAH) is characterised by diffuse pulmonary opacities, respiratory failure, a falling haemoglobin level along with presence of hemosiderin-laden macrophages on bronchoalveolar lavage (BAL). Finding the underlying aetiology of DAH can be challenging but of importance as the treatment and prognosis are largely determined by it. We report a case of DAH with underlying cocaine abuse, a rare cause for the same.
\end{abstract}

\section{Case Report}

A 22-year-old male student, with history of smoking and

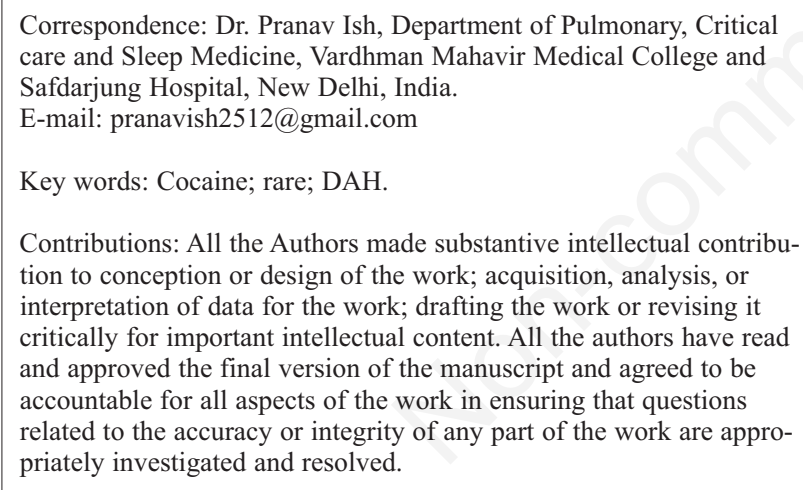
care and Sleep Medicine, Vardhman Mahavir Medical College and Safdarjung Hospital, New Delhi, India.

E-mail: pranavish2512@gmail.com

Key words: Cocaine; rare; DAH.

Contributions: All the Authors made substantive intellectual contribution to conception or design of the work; acquisition, analysis, or interpretation of data for the work; drafting the work or revising it critically for important intellectual content. All the authors have read and approved the final version of the manuscript and agreed to be accountable for all aspects of the work in ensuring that questions related to the accuracy or integrity of any part of the work are appropriately investigated and resolved.

Funding: No funding support was taken for the conduct of the study.

Conflict of interest: The Authors declare no conflict of interest relating to the study.

Informed consent: Written informed consent was obtained.

Received for publication: 24 October 2019

Accepted for publication: 24 January 2020.

${ }^{\circ}$ Copyright: the Author(s), 2020

Licensee PAGEPress, Italy

Monaldi Archives for Chest Disease 2020; 90:1191

doi: 10.4081/monaldi.2020.1191

This article is distributed under the terms of the Creative Commons Attribution Noncommercial License (by-nc 4.0) which permits any noncommercial use, distribution, and reproduction in any medium, provided the original author(s) and source are credited. alcohol consumption for past 4 years presented to the Emergency Room with 3-day-history of low-grade fever, cough and streaky haemoptysis. It was associated with dyspnoea which rapidly progressed to dyspnoea at rest over 2 days. The patient denied any history of chest pain, wheezing, dizziness, syncope, oedema in the lower extremities/limbs, calf pain, unilateral limb swelling, travel, preceding upper respiratory tract symptoms, joint pain, rash, decreased urinary output, and haematuria. There were no systemic co-morbidities or history of drug allergy.

On examination, patient was conscious and oriented to time, place and person. He had tachycardia (heart rate 132/min), and tachypnoea (respiratory rate $36 / \mathrm{min}$ ) with blood pressure of $150 / 89 \mathrm{mmHg}$ and room air oxygen saturation of $60 \%$. Respiratory system examination revealed bilateral basal crepitations. The remainder of the review of systems was unremarkable. Arterial blood gas analysis (ABG) at presentation documented hypoxemic respiratory failure with $\mathrm{pO}_{2} / \mathrm{FiO}_{2}$ ration of 67; suggestive of severe acute respiratory distress syndrome (ARDS) as per the Berlin definition. Point-of-care ultrasonography revealed diffuse bilateral B-lines with no evidence of deep venous thrombosis. Echocardiography was suggestive of left ventricular ejection fraction of $45 \%$ with normal ventricular size, normal valves and no evidence of pericardial effusion. Baseline investigations revealed haemoglobin of $13.5 \mathrm{~g} / \mathrm{dl}$ with a normal leucocyte and platelet count. Liver and kidney function test were normal. Patient was admitted to ICU and initiated on mechanical ventilation with low tidal volume $(6 \mathrm{ml} / \mathrm{kg})$. The patient was started on broad spectrum antibiotic therapy (inj. ceftriaxone + inj. azithromycin). Initial endotracheal aspirate showed the presence of frank blood mixed with mucoid secretion. Repeat haemoglobin value of $11.7 \mathrm{gm} / \mathrm{dl}$ suggested an acute fall in 24 hours. Chest X-ray showed bilateral basal infiltrates (Figure 1A).

During bronchoscopy, serial BAL aliquots demonstrated return of increasingly blood-tinged fluid. The cytology revealed the presence of hemosiderin-laden macrophages (Figure 2) with positive Perl's Prussian blue stain. Thus, the definitive diagnosis of diffuse alveolar haemorrhage (DAH) was made. The systematic approach for identifying the cause of DAH includes evaluation for systemic vasculitis, rheumatic disease, connective tissue disease, infections and other drugs and toxins. The results are presented in Table 1.

The patient was planned for systemic corticosteroids, but, he showed clinically improvement from day 1 of intubation itself; haemoptysis and fever subsided, and he was extubated early on $4^{\text {th }}$ day of ventilatory support. The patient confessed to having smoked freebase cocaine a day prior to onset of his symptoms. The patient showed complete recovery of clinical symptoms and radiological resolution (Figure 1B). 


\section{Discussion}

Cocaine is abused by around 18.2 million people, most of which are young active males [1]. In India, a small proportion of Indians are estimated to be current users of cocaine (males: $0.18 \%$; females: $0.01 \%$ ). The proportion of people using cocaine in harmful and dependent pattern is further less $(0.03 \%)$ [2]. Cocaine is a naturally occurring alkaloid available in four forms: hydrochloride salt, freebase, bazuco and crack. Crack cocaine is the most potent and addictive form with smoking being the preferred method of use [3]. Smoking of cocaine exposes the lung directly to the volatilized drug as well as to the other combustion products of the smoked mixture, thereby increasing the risk of adverse pulmonary effects.

Pulmonary complications of cocaine toxicity include acute
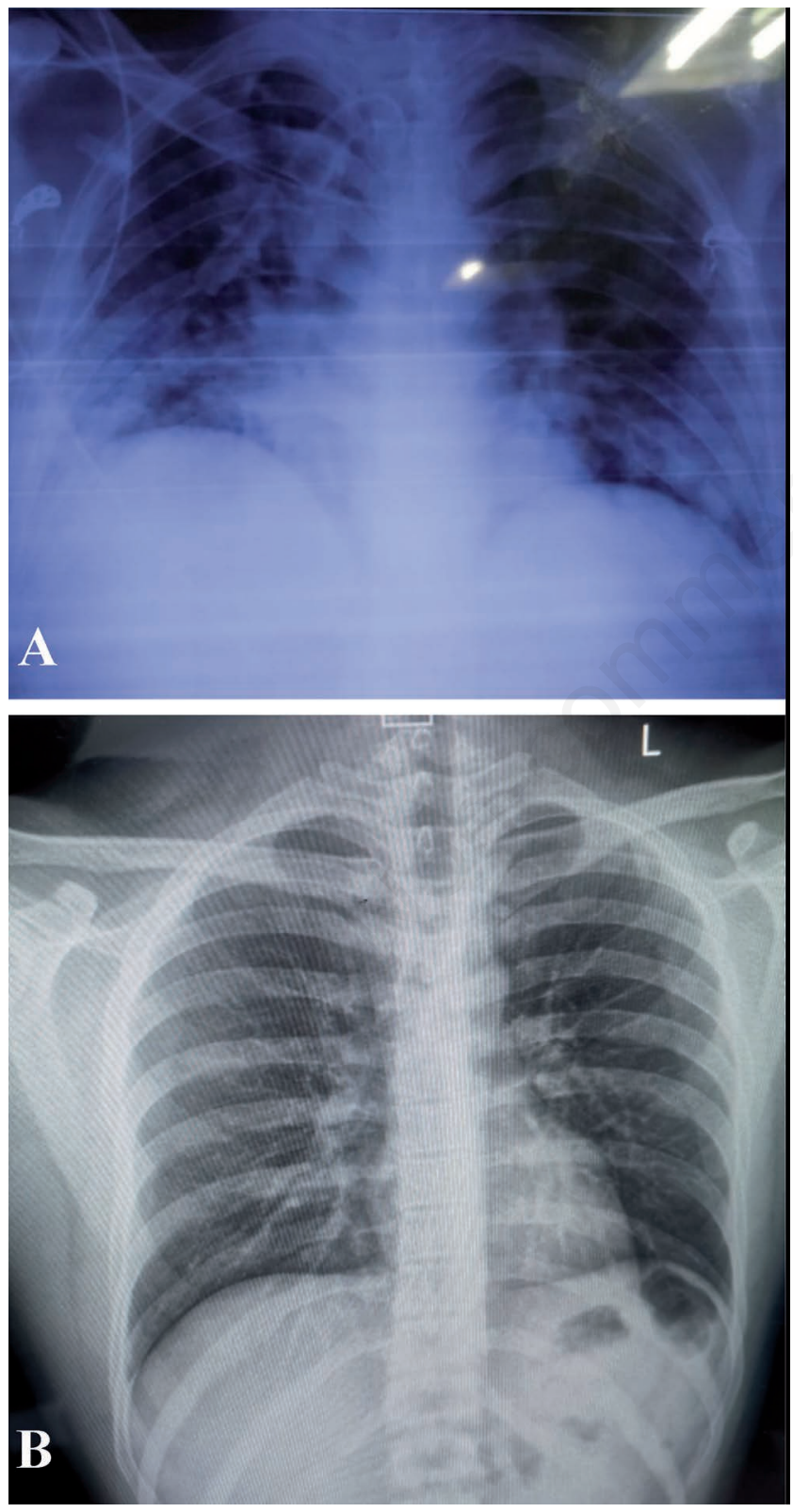

Figure 1. a) Chest $x$-ray showing bilateral diffuse basal infiltrates. B) Chest $x$-ray showing resolution. eosinophilic pneumonia, pneumothorax, pneumomediastinum, pulmonary hypertension and rarely DAH [4]. Due to differences in the pattern of consumption and natural history of cocaine-induced lung diseases, the incidence and exact mechanism is unknown. In our case, numerous other possible causes of DAH were considered and excluded, leaving cocaine-induced DAH as the most likely cause of the patient's presentation. The dramatic improvement without any immunosuppressants argued against a vasculitic process, besides, the negative autoimmune screening tests for the same. In view of spontaneous and rapid resolution, corticosteroids were not given in our patient similar to a recently reported case [5]. In view of rapid resolution of reported cases with supportive care questions the routine use of pulse steroids in DAH, especially in the absence of any autoimmune features. The need of the hour is to collect all these scattered cases of drug induced DAH and attempt to conclude consensus treatment guideline for the same.

Cocaine inhalation may result in alveolar haemorrhage by vasoconstriction of the pulmonary circulation resulting in anoxic cell damage or by a direct toxic effect. Cocaine acts by stimulating adrenergic receptors through increased levels of norepinephrine, and, to a lesser extent, epinephrine producing a sympathomimetic, local anaesthetic, and vasoconstrictive effect [6]. Cocaine producing DAH is often diagnosed as an occult haemorrhage unearthed in autopsy. Evidence of acute or chronic alveolar haemorrhage was found in $71 \%$ of autopsies of patients in whom toxicologic tests for cocaine, conducted by a medical examiner, were positive. In an autopsy series of 20 patients whose deaths were related to cocaine intoxication, $85 \%$ of cases demonstrated pulmonary haemorrhage. Spontaneous resolution of cocaine induced DAH necessitates the focus on supportive management and appropriate ventilatory strategies as literature also reports complications due to barotrauma like pneumothorax [5,7]. The reported cases of cocaine and DAH over the last 15 years are summarized in Table 2 . The cases summarized clearly show that not all the patients were treated with immunosuppressants. However, the survival and treatment given may be related to the severity of disease at presentation. The cases in which the patients survived had spontaneous resolution of DAH without immunosuppression [6,8-14]. The mortality was, however, reported in few cases, with ventilator-associated pneumonia and catheter-associated urinary tract infection being common. This further emphasizes the importance of making the correct etiological diagnosis, else patients with DAH given immunosuppressants for suspected underlying vasculitis can develop opportunistic infec-

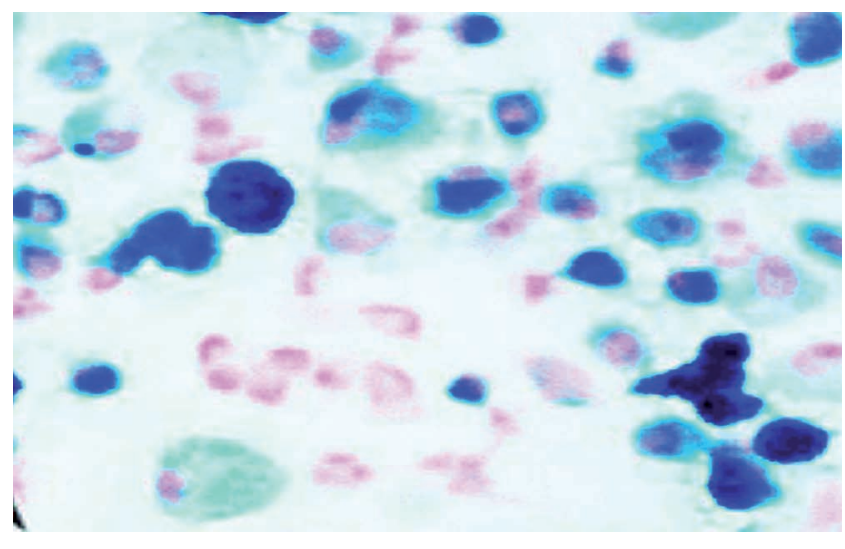

Figure 2. Bronchoalveolar lavage showing hemosiderin laden macrophages. 
tions, thereby, increasing morbidity and mortality [7]. Therapy for DAH consists of treating both the autoimmune destruction of the alveolar capillary membrane and the underlying condition. Corticosteroids remain the gold standard for most patients, espe- cially if associated with systemic or pulmonary vasculitis or Goodpasture's syndrome [15], but may not be advocated as a blanket therapy for all cases. A search for the underlying aetiology determines the treatment and outcome of the patient.

Table 1. Investigations for diffuse alveolar haemorrhage.

\begin{tabular}{lc}
\hline C-ANCA and P-ANCA by immunofluorescence & Negative \\
ANA, anti-CCP, RA factor, anti-dsDNA, anti SS-A, anti SS-B, anti Ul-RNP, direct Coomb's test, anti GBM antibodies & Negative \\
\hline Serum C3 and C4 levels, & Normal \\
Leptospira IgM, Dengue IgM & Negative \\
\hline BAL fluid for AFB stain, fungal stain, CBNAAT, pyogenic culture and Pneumocystis carinii & Negative \\
Serum procalcitonin & $<0.1 \mathrm{ng} / \mathrm{ml}$ \\
\hline Blood culture for pyogenic organisms & No growth \\
2D Echocardiography for valvular lesions & Negative \\
\hline HIV, Hepatitis C RNA, HBsAg, HBeAg, antibodies to HBsAg & Negative \\
APLA (anti lupus anticoagulant, anti-cardiolipin, beta2 microglobulin) & Negative
\end{tabular}

cANCA, cytoplasmic anti-neutrophil cytoplasmic antibodies; pANCA, perinuclear ANCA; ANA, antinuclear antibody; Anti-CCP, anti-cyclic citrullinated peptide; RA, rheumatoid arthritis; ds DNA, double stranded DNA; U1-RNP, U1 ribonucleoprotein; SS, Sjogren's syndrome; CBNAAT: cartridge based nucleic acid amplification test.

Table 2. Clinical studies of cocaine use and alveolar haemorrhage.

\begin{tabular}{|c|c|c|c|c|c|c|}
\hline Author, year, country & $\begin{array}{l}\text { Age } \\
\text { (in years), } \\
\text { sex }\end{array}$ & $\begin{array}{c}\text { Mode of } \\
\text { consumption }\end{array}$ & $\begin{array}{c}\text { Other } \\
\text { addictions }\end{array}$ & $\begin{array}{l}\text { Mechanical } \\
\text { ventilation } \\
\text { and duration }\end{array}$ & $\begin{array}{l}\text { Treatment } \\
\text { and } \\
\text { interventions } \\
\text { received }\end{array}$ & Outcome \\
\hline Gilbert et al. [8], 2006, Belgium & 30 , male & Inhaled & Cannabis & No & Blood transfusion & Stable \\
\hline Mahjoob et al. [9], 2014, Iran & 45 , male & Inhaled & Tobacco & Yes & $\begin{array}{c}\text { Transfusion, } \\
\text { haemodialysis }\end{array}$ & Death \\
\hline Sogomonian et al. [10], 2015, USA & 50 , female & Inhaled & Tobacco, Marijuana & No & $\begin{array}{c}\text { Empirical } \\
\text { antibiotics } \\
\text { acetaminophen, } \\
\text { albuterol, codeine }\end{array}$ & $\begin{array}{c}\text { Survived and } \\
\text { discharged }\end{array}$ \\
\hline Soni et al. [11], 2015, USA & 55 , male & Inhaled & No other addictions & Yes for $<1$ day & $\begin{array}{l}\text { Broad spectrum } \\
\text { antibiotics }\end{array}$ & Death \\
\hline Vidyasankar et al. [12], 2015, Canada & 48 , female & Inhaled & Tobacco & No & LTOT & $\begin{array}{l}\text { Recurrent } \\
\text { admission } \\
\text { leading to } \\
\text { interstitial } \\
\text { fibrosis. } \\
\text { LTOT }\end{array}$ \\
\hline Dushay et al. [6], 2016, USA & 31 , male & Nasal & Marijuana & Yes for 3 days & $\begin{array}{c}\text { Supportive care } \\
\text { Antibiotic therapy } \\
\text { (Vancomycin }+ \\
\text { Piperacillin }+ \\
\text { Tazobactam) }\end{array}$ & Discharged \\
\hline Jimenez et al. [7], 2016, Mexico & 42 , male & Crack & $\begin{array}{l}\text { Tobacco, alcohol, } \\
\text { industrial solvents }\end{array}$ & $\begin{array}{c}\text { Yes for } 20 \\
\text { days with } \\
\text { tracheostomy }\end{array}$ & $\begin{array}{c}\text { Antibiotic, } \\
\text { methylprednisolone } \\
\text { and } \\
\text { plasmapheresis } \\
\text { twice }\end{array}$ & $\begin{array}{l}\text { Death from } \\
\text { pulmonary } \\
\text { sepsis }\end{array}$ \\
\hline Dolapsakis et al. [13], 2019,Greece & 48 , male & Crack & Unknown & No & Antibiotics & Discharged \\
\hline Giacomi et al. [14] & 51, male & Crack & Unknown & No & $\begin{array}{l}\text { Oxygen, } \\
\text { supportive } \\
\text { care }\end{array}$ & Discharged \\
\hline Present study, 2019, India & 22, male & Inhaled & Tobacco, alcohol & Yes for 3 days & $\begin{array}{c}\text { Antibiotics, } \\
\text { supportive care }\end{array}$ & $\begin{array}{c}\text { Survived and } \\
\text { discharged }\end{array}$ \\
\hline
\end{tabular}




\section{References}

1. United Nations. World Drug Report 2016. Report no. E.16.XI.7, United Nations Office on Drugs and Crime, Vienna; 2016.

2. Ministry of Social Justice and Empowerment, Government of India and NDDTC. AIIMS magnitude of substance abuse in India, Report 2019. New Delhi, 2019.

3. Restrepo CS, Carrillo JA, Martínez S, et al. Pulmonary complications from cocaine and cocaine-based substances: imaging manifestations. Radiographics 2007;27:941-56.

4. Terra Filho M, Yen CC, Santos Ude P, Muñoz DR. Pulmonary alterations in cocaine users. Sao Paulo Med J 2004;122:2631.

5. Dushay KM, Evans SK, Ghimire S, Liu J. Cocaine-induced diffuse alveolar hemorrhage: A case report and review of the literature. R I Med J (2013) 2016;99:34-6.

6. Zimmerman JL. Cocaine intoxication. Crit Care Clin 2012;28:517-26.

7. Jiménez-Zarazúa O, López-García JA, Arce-Negrete LR, et al.
Alveolar hemorrhage associated with cocaine consumption. Heart Lung 2018;47:525-53.

8. Gilbert $\mathrm{O}$, Mathieu $\mathrm{D}$, Hanquet $\mathrm{O}$, et al. Hemoptysis in a young man. Rev Mal Respir 2006;23;471-6.

9. Mahjoob MP, Khaheshi I, Paydary K. Diffuse pulmonary hemorrhage after fibrinolytic therapy for acute myocardial infarction in a cocaine abuser patient. Heart Views 2014;15:83-5.

10. Sogomonian R, Alkhawam H, Gandhi V, et al. Refractile foreign material deposits and alveolar hemorrhage in crack cocaine smoker. Respir Med Case Rep 2015;16:48-50.

11. Soni S, Siddiqui O, Puttagunta HK. Crack lung: A rare but potentially fatal complication of cocaine use. Am J Respir Crit Care Med 2017;195:A5559.

12. Vidyasankar G, Souza C, Lai C, Mulpuru S. A severe complication of crack cocaine use. Can Respir J 2015;22:77-9.

13. Dolapsakis C, Katsandri A. Crack lung: A case of acute pulmonary cocaine toxicity. Lung India 2019;36:370-1.

14. Giacomi FD, Srivali N. Cocaine use and crack lung syndrome. QJM 2019;112:125-6.

15. Park MS. Diffuse alveolar hemorrhage. Tuberc Respir Dis (Seoul) 2013;74:151-62. 